\title{
A NEW METHOD FOR SURGICAL TREATMENT OF CYSTS LOCATED IN THE HEAD OF THE PANCREAS \\ Article history:
}

\section{G.D. Odishelashvili, V.A.Zurnajjants, R.K. Ilyasov, D.V. Pakhnov, B.T. Kurtusunov, E.A. Kchibekov, A.N. Detochkin}

Astrakhan State Medical University, Astrakhan, Russia 414000, Astrakhan, st. Bakinsky, 121, Astrakhan State Medical University, e-mail:agma_10@mail.ru,tel.: +79608578785

ABSTRACT - Over the past two decades, the number of patients with cystic formations of the pancreas has increased significantly. Especially the most productive part of the population aged $35-50$ years suffers from this disease. The question of the choice of optimal and rational treatment policy is still an actual problem of modern surgery. The problem of choosing the most radical and at the same time the organ-preserving technique, helping to improve the immediate and long-term results, the quality of life and social and labor rehabilitation, has not lost its relevance, and the studies carried out in this area are currently important.

KEYW ORDS - cyst of the pancreas, internal drainage, pancreatocystogastrostomy.

\section{INTRODUCTION}

Among experts there is no consensus in matters of surgical tactics for pancreatic cysts [2]. The range of surgical interventions performed for pancreatic cysts is quite wide: external drainage of cysts, enucleation of a cyst, various in volume resections of the pancreas together with a cyst (radical operations), the formation of internal fistulae between the cyst wall and various sections of the gastrointestinal tract.

Internal drainage of pancreatic cysts is most prevalent. The frequency of its use reaches from 30 to $60 \%[4,5,6]$.

Indications for internal drainage of pancreatic cysts are $[2,6,7]$ :

1. The presence of single-chamber pancreatic cysts formed with the capsule communicating with the ductal system of the pancreas

2. Cysts of retention

3. The location of pseudocysts in the head of the pancreas

4. Cystic expansion of the main pancreatic duct.

Performing internal drainage is especially advisable when pancreatic cysts are located in the head of the pancreas, since [4]:
Received 21 January 2019

Received in revised form 4 February 2019

Accepted 28 February 2019
1. radical operations are technically difficult to perform, due to the trauma of the pancreas

2. external drainage in most cases is complicated by long-existing external pancreatic and purulent fistulas in $15-30 \%$ of patients, and the rapid closure of the puncture channel, followed by recurrent cyst formation in $20-60 \%$ of patients

The final decision on the formation of a specific type of cysto-digestive anastomosis is made during surgery and depends on many factors including the nature, location, size, number of cysts, degree of maturity, the condition of the wall and characteristics of the contents of the cyst, as well as the condition of the ductal system of the gland.

The main methods of internal drainage are:

1. Cystojejunostomy;

2. Cystogastrostomy;

3. Cystoduodenostomy

Most often, surgeons use cystojejunostomy. Along with the obvious advantages of this method it has disadvantages:

1. Effect of tension of organs stitched together due to short mesentery of the small intestine;

2. Disorders of digestion, malabsorption due to the penetration of pancreatic juice through the anastomosis below the duodenal junction;

3. Adhesive process in the abdominal cavity;

4. Tight fusion of the cyst with the posterior wall of the stomach.

In addition, enterokinases released into the lumen of the small intestine, cause activation of trypsinogen, leading to the destructive action of the anastomosis zone, causing its failure. When applying the longitudinal pancreato-cysto-jejuno-anastomosis, postoperative complications developed in $20 \%$ of cases [6].

Cystoduodenostomy is the rarest variant of internal drainage of pancreatic cysts. Its application is shown in cases when the cyst is located in the head of the pancreas and performing a transventricular operation is difficult for some reason. But at the same time, cystoduodenostomy has drawbacks: significant technical complexity; danger of injury to the pancrea- 
toduodenal vessels and intrapancreatic choledochus. According to C. Frey, when cysto-duodeno-anastomosis was applied, the outcome was fatal in $40 \%$ of patients, and $20 \%$ of those operated on had chronic pancreatitis. [3].

Currently, endoscopic drainage is widely used in the treatment of patients with pancreatic cysts $[5,7]$. This also includes an endoscopic imposition of cystogastro-anastomoses and cystoentero-anastomoses, as well as transpapillary stenting of the pancreatic duct [11]. The disadvantages of these types of operations are: the difficulty of hemostasis in the area of the anastomosis, the impossibility of a thorough revision of the cavity of pseudocyst [10]. The most frequent of them are suppuration of the contents of the cyst as a result of reflux of the contents of the stomach and duodenum, bleeding from the puncture site and fistula in the process of performing transmural access and stenosis of the anastomosis. In addition, when performing transluminal drainage without the use of visualization tools, a perforation of the hollow organ of the abdominal cavity, bleeding from large vessels is possible [9]. Recurrence rate can reach 25\% [9]. In transpapillary drainage, inflammatory changes in the parenchyma and in the main pancreatic duct are the most common complications (35\%) [7, 1]. Less common complications: occlusion of the stent, bleeding, perforation, the addition of infectious complications and migration of the stent. Moreover, the frequency of migration of the stent is $3-15 \%$ [1].

Cystogastrostomy is technically the most simple, fairly safe and appropriate intervention for cysts of the pancreatic head [6]. At the same time:

1. penetration of food masses into the cyst cavity leads to the development of pancreatitis;

2. long-term stagnation of food masses in the cavity of the cyst leads to the development of suppurative processes;

3. powerful peristaltic waves of the stomach can lead to the eruption of the sutures and subsequently to the failure of the sutures.

The desire to reduce the number of common and local postoperative complications forced us to look for new methods of surgical treatment of patients with chronic pancreatitis with pancreatic cysts.

The purpose of the research was to develop a new method of surgical treatment of cysts of the pancreatic head using the pyloric antrum part of the stomach.

\section{MATERIALS AND METHODS}

In the experiment on 12 mongrel dogs, we developed a new method of surgical treatment of cysts of the pancreatic head. A patent of the Russian
Federation No. 2571711 dated November 25, 2015 was obtained for the developed method [8]. The experiments were performed in the laboratory of Astrakhan State Medical University in accordance with the International Recommendations for Biomedical Research using Laboratory Animals (Strasbourg, 1986).

To monitor the degree of inflammatory response and the depth of the pancreatic secretory function in experimental before the operation and at 1-4, 7, 14 day and 1, 3 and 6 months after the operation, serum amylase and blood glucose concentrations were evaluated using an IDEXX VetTest 8008 biochemical analyzer.

The statistic work-out of data was carried out on a personal computer using specialized program Statistica 6.0 for Windows-XP. The following parameters were calculated: $\mathrm{M}$ - arithmetic mean, $\mathrm{m}$ - standard error of the mean, p-level of statistical significance, $\sigma$ standard deviation. Significant differences between the mean values were estimated using Student's t-test with a confidence coefficient $\mathrm{p}<0.05$

\section{RESULTS AND DISCUSSION}

The developed method consists in the following. Under general anesthesia, after median laparotomy, some $5 \mathrm{~cm}$ from the pylorus, both along the greater curvature and minor curvature, after mobilization of areas of the stomach over $3 \mathrm{~cm}$ in the proximal direction, the pyloric part of the stomach was dissected (Fig. 1). Then, through the gaping hole of the pyloric stomach, puncture of the cyst of the pancreatic head was performed, the back wall of the pyloric and anterior wall of the cyst of the pancreas was dissected over $3 \mathrm{~cm}$. The contents of the cyst were removed, an endoscopic revision of the cyst was performed. Having achieved thorough hemostasis, then we sutured the formed "front lip" of the future fistula between the posterior wall of the pyloric department and the anterior wall of the cyst with a continuous suture with absorbable material (vicryl) (Fig. 2). After that, the pyloric orifice was sutured tightly with a single-row suture using an atraumatic thread (Fig. 3). The continuity of the gastrointestinal tract was restored by imposing an anastomosis between the stomach and the jejunum on the type of end to side (Fig. 4).

The proposed method of pancreatocystogastrostomy includes:

1. Isolation of the fistula zone from food masses, which is the prevention of the development of pancreatitis and suppurative processes;

2. Obstacle of activation of trypsinogen due to the weakly acidic environment of the pyloric department, which is the prevention of the development of insolvency of fistula sutures and secondary bleeding; 


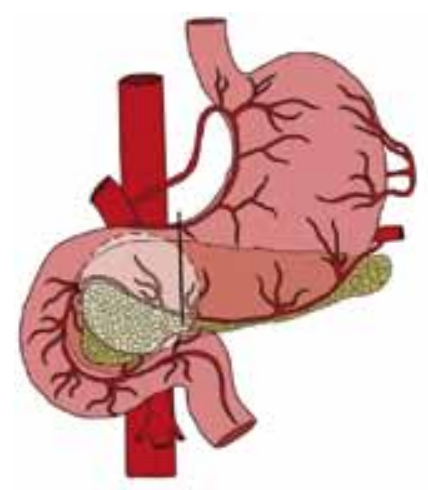

Fig. 1.

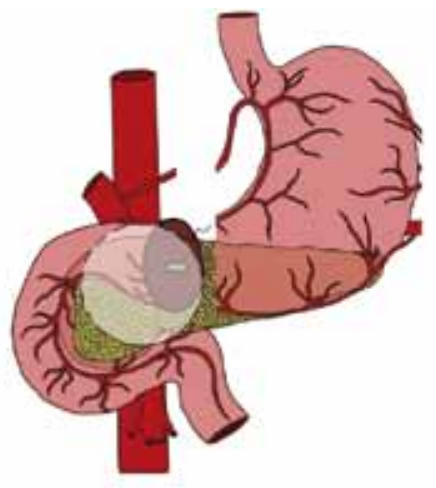

Fig. 2.

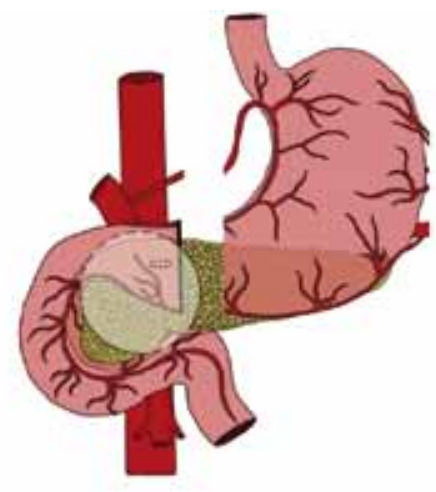

Fig. 3.

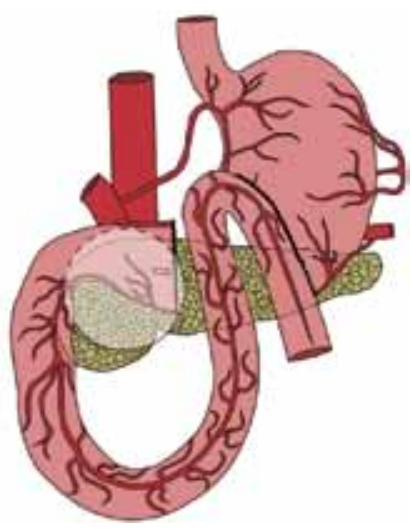

Fig. 4.
3. The lack of powerful peristaltic waves of the pyloric part of the stomach, preventing tension of the anastomotic zone, which is a prevention of insolvency of fistula sutures;

4. The lack of the effect of the tension of the organs due to the proximity of the pyloric part of the stomach to the pancreas, which is the prevention of the failure of the anastomotic sutures.

The results of dynamic monitoring of serum amylase and blood glucose concentrations in operated animals are presented in table 1 .
$-1412 \pm 10.2$ (units/l); blood glucose $-9.4 \pm 0.24$ $(\mathrm{mmol} / \mathrm{l})$, and by the $3^{\text {rd }}$ month all indicators almost reach baseline values.

\section{CONCLUSIONS}

Summarizing the data obtained during the experiments, we found that the draining operation of pancreatocystogastrostomy using the pyloric antrum of the stomach is technically feasible and does not lead to any functional impairment of the general condition of the animals, except for the first 3-4 days after

Table 1. The average values of blood amylase and blood glucose before and after pancreatocystogastrostomy.

\begin{tabular}{|c|c|c|c|c|c|c|c|c|c|}
\hline \multirow{2}{*}{ Research date } & \multirow{2}{*}{$\begin{array}{l}\text { Number of } \\
\text { cases }\end{array}$} & \multicolumn{4}{|c|}{ Blood amylase (units / I) } & \multicolumn{4}{|c|}{ Blood glucose (mmol / I) } \\
\hline & & M & $\pm \mathrm{m}$ & $\pm \sigma$ & $P>$ & M & $\pm \mathrm{m}$ & $\pm \sigma$ & P> \\
\hline Before surgery & 12 & 648 & 1,5 & 2,4 & 0,01 & 4,8 & 0,04 & 0,22 & 0,01 \\
\hline 1 day & 12 & 1828 & 2,4 & 10,6 & 0,04 & 13,4 & 0,03 & 0,18 & 0,01 \\
\hline 2 day & 12 & 1796 & 2,3 & 8,8 & 0,04 & 13,1 & 0,03 & 0,16 & 0,01 \\
\hline 3 day & 12 & 1748 & 2,3 & 8,2 & 0,04 & 12.9 & 0,02 & 0,17 & 0,01 \\
\hline 4 day & 12 & 1622 & 2,2 & 9,2 & 0,03 & 12,7 & 0,08 & 0,36 & 0,01 \\
\hline 7 day & 12 & 1412 & 2,4 & 10,2 & 0,04 & 9,4 & 0,07 & 0,24 & 0,01 \\
\hline 14 day & 12 & 864 & 2,2 & 8,2 & 0,02 & 7,9 & 0,04 & 0,15 & 0,01 \\
\hline 1 month & 9 & 746 & 2,3 & 8,7 & 0,03 & 7,8 & 0,05 & 0,15 & 0,01 \\
\hline 3 months & 6 & 686 & 1,7 & 1,9 & 0,01 & 6,85 & 0,04 & 0,1 & 0,01 \\
\hline 6 months & 3 & 658 & 1,8 & 1,9 & 0,01 & 5,2 & 0,04 & 0,12 & 0,01 \\
\hline
\end{tabular}

As a result of biochemical analysis, it was found that on the first day after surgery an increase in amylase occurs from $648 \pm 2.4$ (units/l) to $1828 \pm 10.6$ (units/l), that is, 2.9 times, and glucose blood from $4.8 \pm 0.22$ $(\mathrm{mmol} / \mathrm{l})$ to $13.4 \pm 0.18(\mathrm{mmol} / \mathrm{l})$, that is, 2.8 times. Starting from the $7^{\text {th }}$ day after the operation, these indicators show a steady decline (blood amylase operation. Good results made it possible to apply this method in the clinic in 5 patients. Operated patients were examined after 5 years. All patients recovered. No complaints. Patients do not have a deficiency of body weight, they have retained the ability to work. This method can be applied in clinical practice. 


\section{REFERENCES}

1. BikhChandani J., SUraweera D.B., Upchurch B.R. "Multiple pancreatic pseudocysts treated with endoscopic transpapillary drainage". Clinics and Practice. 2013. V.3, \#1. P.10-19.

2. Danilov M.V., Fedorov V.D. "Pancreas surgery: a guide for physicians”. - Moscow, 1995. - 512 p.

3. Frey C.F. Comparison of local resection of the head of the pancreas combined with longitudinal pancreaticojejunostomy (Frey procedure) and duodenumpreserving resection of the pancreatic head (Beger procedure) / C.F. Frey, K.L. Mayer / World J Surg. - 2003. - Vol. 27. - P. 1217-1230.

4. Grishin I.N., Grits V.N., Lagodich S.N. "Cysts, pancreatic fistulas and their complications". - Minsk, 2009. $-272 \mathrm{p}$.

5. Karyukhin I.V., TaRasenko S.V., RakHMaEV T.S., Zaitsev O.V., FatKina S.N. Modern approaches to the treatment of pancreatic cysts in chronic pancreatitis. Siberian medical journal. 2013. No. 5. P. 5-12.

6. Kubyshkin V.A., Kozlov I.A., Krieger A.G., ZHAO A.V. Surgical treatment of chronic pancreatitis and its complications.The Annals of surgical hepatology. 2012. № 4. P. 24-35.

7. NEALON, W.H. Surgical management of complications associated with percutaneous and/or endoscopic management of pseudocyst of the pancreas / W.H. Nealon, E. Walser // Annals of Surgery. - 2005. - Vol. 241, № 6. - P. 948-960.

8. Odishelashvili G.D., IL'JAsov R.K. A method of surgical treatment of cysts of the pancreatic head. Patent RF, no. 2571711, 2015

9. Ramsey M.L., Conwell D.L., Hart P.A. "Complications of chronic pancreatitis”. Dig Dis Sci, 2017. V. 32, \#7, P. 1746-1750. doi: 10.1007/s10620-0174518-x.

10. SIAL, G.Z. Endoscopic cystogastrostomy: minimally invasive approach for pancreatic pseudocyst / G.Z. Sial, A.Q. Qazi, M.A. Yusuf // APSP Journal of Case Reports. - 2015. - Vol. 6, № 1. - P. 4-9.

11. Zerem, E. Minimally Invasive Treatment of Pancreatic Pseudocysts / E. Zerem, G. Hauser, S. Loga-Zec, S. Kunosic Kunosic, P. Jovanovic, D. Crnkic // World Journal of Gastroenterology. - 2015. - Vol. 21, № 22. - P. 6850-6860. 